\title{
La argumentación en la sentencia laboral: un análisis en torno al proyecto de reformas al Código de Trabajo (expediente № 15.990)
}

\author{
M.Sc. Jorge Olaso Álvarez \\ Juez del Tribunal Segundo Civil de San José, Sección Primera, Profesor de la Facultad de Derecho de la Universidad de \\ Costa Rica, Profesor de la Maestría en Derecho Laboral y Seguridad Social de la UNED, Facilitador de la Escuela Judicial \\ de la Corte Suprema de Justicia. \\ E-mail: jeolaso@yahoo.com
}

Recibido: Enero 2015 • Aceptado: Febrero 2015

\section{RESUMEN}

\begin{abstract}
"El artículo analiza los cambios aplicados en la legislación laboral, en el marco de la posible entrada de un nuevo Código de Trabajo, así como los diferentes parámetros argumentativos que posiblemente puede incidir en la adecuada fundamentación de la sentencia"
\end{abstract}

Palabras claves: hechos, argumentación jurídica, motivación de la sentencia, narrativa fáctica, congruencia, prueba para mejor proveer, bases.

\section{ABSTRACT}

The argumentation in the labour judgement: an analisis centered in the proyect of amendments in the work code. (File no. 15.990)

\begin{abstract}
"The article analyzes the changes in labor laws applied in the context of the possible entry of a new Labour Code and argumentative different parameters that can possibly affect the proper grounds of the judgment"
\end{abstract}

Key words: facts, legal arguments, reasoning of the judgment, factual narrative, consistency, proof to provide better, base.

\section{Antecedentes}

Dentro del contexto de reformas que se pretenden implementar en el campo procesal laboral, merece una especial referencia lo dispuesto por el párrafo $3^{\circ}$ del artículo 560 de la Ley de Reforma Procesal Laboral, cuyo veto inicial decretado por la ex presidenta Laura Chinchilla Miranda fue recientemente levantado por la administración del actual presidente Luis Guillermo Solís Rivera. Valga destacar que dicho levantamiento ha sido objeto de dos acciones de inconstitucionalidad planteadas ante la Sala Cuarta, y que corresponden a los números 1419542-0007-CO y 15-54-0007-CO.

Independientemente de la condición en que se encuentra dicha reforma, la importancia de la norma indicada radica en que ella establece una serie de lineamientos que deben cumplir las sentencias. Estos difieren en gran medida de los parámetros formales, que en la actualidad, cumplen las sentencias en esta materia, por remisión expresa del artículo 452 del Código de Trabajo, al numeral 155 del Código Procesal Civil. A efecto 
de resaltar estos aportes de la reforma, se desarrollará cada uno de los supuestos contenidos en el párrafo $3^{\circ}$ citado.

\section{Hechos y prueba}

Primeramente, el párrafo $3^{\circ}$ del artículo 560 establece la obligación de consignar una síntesis de las pretensiones y las excepciones aducidas, sobre este aspecto no se hará menor referencia, dado que se trata simplemente de una transcripción literal de esos elementos. De seguido, la norma dispone la necesidad de consignar en forma clara, precisa y ordenada cronológicamente los hechos probados y no probados de importancia para resolver.

La circunstancia de que la consignación de los hechos debe ser clara, conlleva todo un avance en cuanto a la formulación estructural de los mismos, pues hasta ahora las normas que hacen referencia a las formalidades del fallo no exigen esa condición respecto a esos hechos. En este sentido, el actual Código de Trabajo no cuenta con una disposición legal que regule la estructura que debe cumplir una sentencia en esa materia, por lo que el artículo 452 ibídem permite utilizar, como fuente supletoria, el numeral 155 del Código Procesal Civil, el cual establece que solo es necesario efectuar una indicación de los hechos acreditados.

Ahora bien, el tema de la claridad de los hechos refleja la importancia que se le da en la actualidad a ese requisito dentro del silogismo lógico de la sentencia. En el presente trabajo no se pretende desarrollar el tema de la argumentación jurídica y su vinculación con la función jurisdiccional, pero es importante analizar la importancia del desarrollo eficaz del considerando sobre "hechos probados" como andamio esencial que sostiene la estructura del fallo.

El problema de los hechos y su vinculación con la efectiva fundamentación del fallo ha sido por gran parte de la doctrina. Así, el autor Rudner (1966) se refiere al conocimiento judicial de los hechos, dentro de lo que él denomina "contexto de descubrimiento" (p. 22), como el iter que lleva al juez a formular los enunciados de los hechos que juzga ${ }^{1}$. Dichos enunciados muchas veces se vinculan conceptualmente con el tema "verdad", entendida esta como un ajuste cercano a la "realidad".

Son muy pocas las situaciones en que esas aproximaciones a la verdad se logran a través de lo que se llega a clasificar como "prueba directa". Esta se entiende como la que surge a través de una "observación empírica" de los hechos, y la apreciación adecuada de la prueba que los acredita. claro ésta de la utilización de los sentidos del juzgador ${ }^{2}$.

Evidentemente, son los casos, tanto en la materia laboral como el resto de los campos del derecho, en se requiere una decisión jurisdiccional en la que el juez puede acudir a este tipo de medio de prueba. De esta forma el conocimiento de los hechos llega a ser mediato e indirecto, o sea "inferido de, o sugerido por otro conocimiento ulterior u otro fundamento o base de conocimiento"3; en otras palabras, a través de una inferencia de otros medios de prueba o enunciados efectuados por las partes.

Estas circunstancias se presentan muy especialmente en el campo del derecho de trabajo, debido a las situaciones que a continuación se expondrán. Primeramente, la narración fáctica contenida en la demanda laboral muchas veces no pasa por el "filtro técnico" de un profesional en derecho, ya que el trabajador acude al despacho judicial a plantear su acción, tal y como lo permite el numeral 463 del Código de Trabajo. Dicha manifestación del principio de gratuidad, que busca potencializar a su vez una tutela judicial efectiva (artículo 41 de la Carta Magna), provoca un planteamiento incorrecto e inadecuado de los hechos que rodean al reclamo del trabajador. Esto porque en la práctica de cada juzgado

1. R.S. Rudner, Filosofia de la Ciencia Social, (1966), traducción de D. Cano, Madrid, Editorial Alianza, 1966, p. 22.

2. Gascón Abellán, Marina. Los hechos en el derecho. Bases argumentales de la prueba. Editorial Marcial Pons, Madrid, 2004.

3. Esta cita corresponde a la obra La percepción y el mundo físico de D.M. AMSTRONG, el cual es reseñado por Marina Gascón Abellán en la obra dicha. 
es normal que el técnico encargado de recibir esas gestiones utilice una plantilla o machote, para cada uno de los casos que se presentan.

La práctica anteriormente mencionada, provocada por la gran cantidad de asuntos a los que tiene que hacer frente la institución, genera que la descripción del hecho no sea la más acertada en aras de obtener esa tutela, lo que a su vez incide en el aspecto de las pretensiones y de las pruebas. A pesar de la experiencia que puede gozar este tipo de funcionarios, muchas veces se omite plasmar en la demanda situaciones esenciales para la decisión del asunto, lo que produce una serie de dificultades para la elaboración del enunciado de hechos probados. Esto sin tomar en cuenta que el ofrecimiento de la amplia gama de prueba adecuada para respaldar los hechos, es desconocida por el auxiliar, quien se limita a introducir las que se utilizaron en la "plantilla" referente a otro caso. Y ello sin tomar en cuenta las imprecisiones terminológicas que, a pesar de la asistencia letrada, puede generar el trasladar la visión del caso que tiene la parte trabajadora o la empleadora, desde la perspectiva de un lenguaje común a lo que se denomina "lenguaje jurídico"4. En otras palabras, transmutar el lenguaje "común" a una peculiar jerga, propia de un grupo socio-profesional que ostenta una forma de hablar y de escribir sujeta a ciertos usos especiales de dicho lenguaje ${ }^{5}$. En esta traducción de lo "común" a lo "jurídico", por ejemplo, se pasa de una "merma en el

4. Haba señala que el "lenguaje jurídico" es un universo de discursos que se compone del heterogéneo conglomerado lingüístico integrado por: a. las disposiciones expresas que a título de derecho positivo edictan las autoridades políticas (Poder Legislativo, Administración, etc.) de un país; b. junto con todas las formulaciones que emplean o reconocen como parte de la literatura técnica de su profesión los operadores del derecho (jueces, abogados, etc.), los académicos de esa materia (docentes, doctrina, etc.) y en general quienes integran el sector identificado específicamente como los "juristas". HABA, Enrique Pedro. "El espejismo de la interpretación literal: Encrucijadas del lenguaje jurídico". Tomo I, pág. 11.

5. Haba, ob-cit. Pág. 12. salario" a un jus variandi abusivo, de un "accidente en el camino al trabajo" a riesgo in itinere, o de un "correo electrónico remitido al empleador, en forma insultante" a una falta grave por pérdida de confianza objetiva, entre otros.

Este fenómeno resulta irrelevante cuando esa traducción idiomática se efectúa en el marco de la creación normativa o del discurso universitario propio de la carrera de Derecho, pero cuando ello se plasma en la redacción de los hechos de la demanda y su enunciación en un fallo genera, en no pocas oportunidades, problemas de difícil solución. Esto debido a que dentro de lo que debería ser una narración fluida y cronológica de los hechos relevantes se incorporan conceptos técnicos (lo que implica conclusiones interpretativas), propias de otras etapas del análisis jurídico. Esta situación dificulta la labor jurisdiccional en dos fases: la primera, en la admisión, práctica y valoración de la prueba, y, segundo, en el dictado de la sentencia.

Lo primero ocurre debido a que, al enfrentar el problema de decidir qué prueba admitir, el juzgador se encuentra con el problema de que los hechos, lejos de ser una afirmación realizada por las partes, se encuentran cimentados en conceptos jurídicos (buena fe, pérdida de confianza, acoso laboral, comisiones, subsidio salarial, etcétera). En la práctica y valoración de la prueba se pretende que el testigo (en la mayoría de los casos una persona ajena al lenguaje propio de un operador del derecho) haga referencia en su declaración a esa terminología técnica narrada en los hechos, lo cual evidentemente no es así y, aun cuando lo hace, coloca en un estado de poca credibilidad lo testificado, precisamente porque resulta inusual que una persona acostumbrada a utilizar otro "tipo" de lenguaje recurra a este. Lo anterior también se refleja en la elaboración del enunciado de hechos probados y no acreditados del fallo, dado que el juez se ve en la obligación de desvincular lo fáctico de la conclusión técnica inmersa en el hecho, lo que incluso lo puede llevar a incurrir en incongruencias al tener que "inferir" hechos que ni tan siquiera la parte ha introducido en su líbelo de demanda o de contestación. 
Esta problemática es reseñada por Pedro Haba (2003), quien se refiere a diversos estudios en torno a la distinción entre lenguaje-objeto (lenguaje legal) y metalenguaje (lenguaje de los juristas). Haba destaca que para dicho autor los llamados comentarios doctrinales o formulaciones jurisprudenciales y los alegatos conclusivos, con que los abogados inundan la narración de los hechos en sus escritos de demanda o de contestación, pretenden proponer una argumentación relativa a las normas aplicables a la teoría del caso, por lo que muchas veces dentro de los hechos se incluye un contenido explícito o implícito de la ley misma ${ }^{6}$.

Ahora bien, no con ello no se procura dejar de lado que el lenguaje utilizado en la narración de los hechos va unido muchas veces con valoraciones. Sin embargo, lo que se está criticando es que muchas veces esa valoración se encuentra condicionada al parámetro normativo fijado en la norma. Es claro que el lenguaje no solo va dirigido a reproducir, bajo formas simbólicas, aspectos del mundo exterior; sino que sirve para introducir un orden en esos aspectos y también someterlos a unas valoraciones, o sea a un modo de ver la realidad. Es por esto que se habla de las distintas funciones del lenguaje: a) descriptivo (brinda información); b) emotivo (sentimientos); c) prescriptivo (mandatos y reglas) y lo estimativo (valores) ${ }^{7}$.

Por consiguiente, muchas veces estas funciones se entremezclan en el planteamiento de los hechos por las partes y la reconstrucción de éstos a través de la sentencia. Por un lado, puede

6. HABA, Pedro. Op.cit. pág. 15.

7. Haba señala que muchas más funciones más: entre ellas, interrogar, saludar, pedir, aconsejar, bromear, insultar, celebrar, autorizar, bautizar, prometer, investir, etc. Incluso cita a WITTGENSTEIN quien señala que las funciones de las palabras se asimilan a las herramientas en un cajón de herramientas: hay un martillo, una tenaza, una sierra, un destornillador, una regla, un tacho de cola, cola, clavos y tornillos. Tan distintas como las funciones de estos objetos son las funciones de las palabras, y aun así existen similitudes entre ambas. Haba, Pedro. Op. cit. pág. 29. ser que a través de éstos se busque brindar información acerca de las circunstancias que rodean la relación laboral y el porqué de su finalización; también puede tener un plano emotivo cuando se narran circunstancias de esa condición. Por ejemplo, dentro del contexto de la depresión o angustia que pudo generar el ejercicio abusivo de una acción de despido del empleador.

Quizás el plano más cuestionable en la utilización de las funciones del lenguaje, dentro de la narración de los hechos, se produce en la dimensión prescriptiva y en la estimativa. Esto producto de que, en la elaboración técnica, tanto de la acción como en el dictado del fallo, se recurre a la mención de contextos normativos y jurisprudenciales, quizás con la idea de dar fundamentos de peso a la narración, pero a través de esto se pierde la idea esencial de la narrativa de los hechos. Las normas y los antecedentes de los tribunales escapan del contexto de la afirmación de hechos relativos al caso que buscan "convencer" al órgano jurisdiccional para el dictado de una decisión.

Lo mismo sucede en el ejercicio de la función estimativa, pues en ella el litigante incurre en la construcción de conclusiones relativas a la forma en cómo deben ser apreciados los hechos y los eventos. En otras palabras, la introducción de valoraciones en torno a normas prescriptivas y juicios de valor en uno u otro sentido, no deberían integrarse en la construcción histórica de la acción o del fallo, sino que son parte del fundamento jurídico técnico que el operador del derecho debe brindar para hilvanar los hechos y luego, subsumirlos, en el planteamiento normativo adecuado para el caso.

Esta problemática la encuentra el juzgador al analizar los hechos planteados en la demanda, pues las partes introducen conclusiones dentro de éstos hechos, lo que deja de lado situaciones que tendrían una relevancia capital en uno u otro sentido. Esa omisión no puede ser subsanada por el juez, pues a pesar de que gracias a la prueba evacuada pueda inferir hechos esenciales para el dictado de la decisión, la incorporación de éstos no sería factible por violentar el principio de congruencia. Tal circunstancia se podría obviar bajo 
la perspectiva de cada uno de los sistemas procesales, lo que en el campo laboral se centraría en derivaciones del principio protector y el de la búsqueda de la verdad real, pero colocaría al empleador en un marco de desigualdad procesal, sobre todo cuando es el propio órgano jurisdiccional el que busca llenar los vacíos fácticos que la parte proponente no cumplió al interponer su acción.

En la práctica judicial actual tal hipótesis ocurre en múltiples ocasiones. Esto es en casos en los que al momento de elaborar el considerando de hechos probados de la sentencia, el juez se encuentra con la sorpresa de que la narrativa de los hechos de la demanda se encuentra investida de una serie de conclusiones y citas normativas o jurisprudenciales. El instrumento procesal que se utiliza para solventar esta problemática es el numeral 489 del Código de Trabajo. Esto porque dicha norma, en su párrafo segundo, permite al juzgador solicitar en forma explícita la prevención a las partes para que suplan la falta de bases para poder resolver de una vez en sentencia cuestiones de fondo del juicio junto con las indemnizaciones correspondientes. Dicha acción se debe cumplir dentro de un plazo de ocho días, bajo el apercibimiento de desestimar en sentencia los puntos acerca de los cuáles no haya sido acatada la orden.

De esta forma, se asimila los términos " $b a$ ses" y "hechos" para subsanar esas falencias en la narración efectiva de los hechos, para así proceder a resolver en torno a las indemnizaciones pretendidas por la parte trabajadora. Usualmente, esta práctica es utilizada para favorecer a esa parte, utilizando como argumentos esenciales conceptos jurídicos indeterminados como los antes mencionados (principios de tutela judicial efectiva, búsqueda de la verdad "real” y más específicamente derivaciones del principio protector).

La intención del presente trabajo criticar esas interpretaciones, ya que sus fundamentos radican en corregir, subsanar y, hasta muchas veces, incorporar hechos no relatados por la parte actora en su demanda. No se puede dejar de mencionar que esta práctica le genera un desequilibrio al empleador, quien se ve obligado a cambiar de táctica de defensa de forma sorpresiva, cuando simplemente se le notifica una corrección de los hechos de la demanda y se le otorga un plazo relativamente corto (ocho días) para referirse a esa modificación y ofrecer prueba que rebata la nueva construcción fáctica.

En conclusión, el objetivo del presente estudio es reflejar las situaciones que se presentan en la elaboración clara y cronológica de los hechos probados e indemostrados, tal y como lo dispone el párrafo tercero del numeral 560 del proyecto al Código de Trabajo. Esa función esencial para la elaboración de los argumentos en la decisión jurisdiccional puede verse truncada si las partes no aprecian la importancia de elaborar en forma precisa, concatenada y elaborada el marco fáctico de la demanda.

Una demanda mal elaborada generará una contestación defectuosa, pero sobre todo una infracción grave al principio de defensa que, a su vez tiene la parte empleadora, dado que en muchos casos resulta difícil defenderse no en cuanto a los hechos, sino a las conclusiones e interpretaciones dogmáticas o normativas o lo que es peor debatir citas jurisprudenciales incorporadas dentro de una mención de hechos "relevantes" del proceso. Esa práctica incorrecta en la narrativa fáctica imposibilita, en principio, la labor jurisdiccional que le ordena el párrafo tercero de la norma citada, pues en ella se dispone que una fundamentación "adecuada" se basa en establecer "las razones de hecho", jurídicas, doctrinales y jurisprudenciales que lleven a la procedencia o improcedencia de las proposiciones.

\section{Referencias bibliográficas}

Haba, Pedro Enrique. (2003) El espejismo de la interpretación literal. Encrucijadas del lenguaje jurídico. San José: Escuela Judicial.

Gascon, Marina. (2004) Los hechos en el Derecho. Bases argumentales de la prueba. Madrid: Marcial Pons.

RUdner, Rita .S. (1966) Filosofía de la ciencia social. Madrid: Editorial Alianza

VArgas, Eugenio. (2000) Código de Trabajo. San José: Investigaciones Jurídicas S.A. 
